\title{
La modernización de los municipios en Tabasco, 1983-1987
}

\author{
Adrián Gabriel Delgado Lara
}

\section{Introducción}

Durante la campaña política de Miguel de la Madrid por la presidencia de la república, se propuso una profunda reforma municipal que dotaría a las comunidades de "los instrumentos políticos, administrativos y económicos para gobernar, organizar y encauzar mejor la inmensa fuerza potencial creadora del municipio, a fin de que ellos mismos pudieran generar el desarrollo de sus comunidades urbanas y rurales".'1

Al inicio de su gobierno, De la Madrid promovió ante el Congreso de la Unión una reforma al artículo 115 de la Constitución, en la cual se ampliaban sustancialmente el poder y las funciones del gobierno municipal, proponiendo la participación de la comunidad en las decisiones y la tarea de emprender acciones en favor de su desarrollo.

Estos dos hechos colocaron al municipio en el nivel central de la discusión. Se señaló que el municipio se hallaba entre la sociedad y el Estado; en la primera como un espacio de su acción y en el segundo como una pieza fundamental de la práctica del poder en el sistema político mexicano.

La descentralización de la vida nacional hacia el municipio sería motivo de discusión, no sólo en los recintos académicos; se ha indicado que la descentralización, en tiempos de profunda crisis, es parte de un proceso de reparto de compromisos y no de soluciones; se señalaba también que la paradoja de la descentralización es que ésta se lleva a cabo centralizando la capacidad de toma de decisiones, realizada en los altos niveles de gobierno y entre grupos reducidos.

Antes de finalizar esta nota introductoria, dos anotaciones acerca del escenario estatal.

El estado de Tabasco, con una superficie de $24665 \mathrm{~km}^{2}$, está constituido por 17 municipios, los cuales se han agrupado históricamente en cuatro regiones denominadas la Chontalpa, el Centro, la Sierra, los Ríos.

Cada una de las regiones presenta características que la hace unidad homogénea y reconocible entre ellas. Por ejemplo, la Chontalpa es la región más poblada (44.9\% de la población estatal) y la más diversificada en cuanto a su producción, en cambio la región de los Ríos es la menos poblada $\left(17.24 \mathrm{hab} / \mathrm{km}^{2}\right)$ y la PEA se ocupa primordialmente en el sector agropecuario.

1 Miguel de la Madrid, Siete tesis de gobierno, Presidencia de la República, Méxiro, 1982. 
En lo político, la administración pública estatal coincide en tiempos políticos con la administración federal, lo que permite espacios de maniobra entre ambos niveles de gobierno, en tanto comunidad de políticas y de la posibilidad de acceder oportunamente a recursos financieros federales.

\section{Antecedentes}

En Tabasco la descentralización partió de una idea general: "México es una nación de pequeñas comunidades, de municipios. Somos un estado federal, y federalismo es descentralización. Uno de los aspectos fundamentales de esta descentralización reside en el fortalecimiento democrático del municipio."2

En la entidad, fortalecer la instancia municipal habría de traducirse en dos tipos de acciones: la jurídica y la administrativa, ambas dirigidas expresamente hacia la organización de la capacidad operativa del municipio.

La descentralización no se entendió como un nuevo campo de lucha del federalismo, sino como una negación del proceso de centralización.

La descentralización no era describir una realidad presente sino enfrentarse con ella. Se trataba de llevar a la práctica el federalismo que está plasmado en la Constitución.

El hecho de que la campaña política para gobernador coincidiera con la campaña presidencial, logró conjuntar las propuestas y ponerlas en marcha en Tabasco. El referente legal fue el artículo 124 constitucional, el cual marca que lo no escrito expresamente en la Constitución en materia de gobierno interior, es asunto de cada uno de los estados federados. El nuevo gobernador lo expresó de la siguiente forma: "Lo que falta es retomar los orígenes para avanzar más rápido."”

La modernización del municipio partía del reconocimiento de la realidad de estas entidades en los años de 1982 y 1983; la transformación no sería fácil, pues las modalidades tradicionales de la primera instancia de gobierno no podian desaparecer de un plumazo.

La cotidianeidad mostraba la siguiente escena: "Los presidentes municipales atienden muchísimas demandas de individuos y grupos, que son en su mayoría peticiones; con mayor frecuencia en las áreas rurales, la gente del campo se acerca al ayuntamiento para suplir sus carencias, recurriendo a la 'bondad' del presidente municipal, que otorga bienes y servicios a sabiendas de que la opinión pública le sería favorable."4

Resultaba obvioque ningún presupuesto sería suficiente para satisfacer la inercia de esta tradición paternalista tan fuertemente arraigada en los municipios del país, la misma situación se presentaba en diferentes tonos en Tabasco.

Se hizo explícito que el "paternalismo es la cara opuesta de la democracia, que es casi su negación, pues deposita en un solo hom-

2 "Curso, balance y perspecriva de la Revolución Mexicana", Expediente, Comisión Nacional de Ideología, PRI, núm. 2, 1983.

3 Enrique González Pedrero, Una democracia de carne y hueso. Ed. Océano, México, 1987, p. 32.

4 lbidem, p. 36 . 
bre la facultad y la 'gracia' de repartir todos los bienes de la sociedad". ${ }^{5}$

Como una vía alternativa se concibió al municipio como una comunidad organizada y activamente participativa, con capacidad política, jurídica y administrativa, que "debe apoyarse en la planeación democrática para fortalecerse como la instancia de gobierno más cercana al pueblo, pues en él se registran las demandas básicas de la población y la participación social. Es, pues, un espacio que tiene amplias posibilidades de desarrollo". ${ }^{6}$

La planeación democrática, en su aplicación en Tabasco, pretendía evitar el dispendio de recursos y el derroche de los esfuerzos; esta finalidad era buscada por tres vías: continuidad de los programas, eficacia en los resultados y coherencia en las decisiones.

Un segundo aspecto tenía que ver con la participación popular; para que el sistema funcionara no bastaba que la sociedad política se obligara a actuar en determinado sentido si la sociedad civil lo hacía en sentido opuesto o no estaba de acuerdo. Frente a esta situación el Estado tenía dos alternativas: "imponer su decisión por la vía de la fuerza o apegar su actuación a la voluntad soberana". ${ }^{7}$

De lo anterior se desprendió la característica democrática de la planeación, y la institucionalización de la participación ciudadana. La finalidad era la racionalidad, la participación ya no era fruto del azar o del voluntarismo, sino una actividad consciente y organizada.

Este nuevo espacio daba lugar a alternativas adecuadas a los problemas y circunstancias locales y permitía la recuperación del gobierno municipal por su comunidad, transformándolo en el principal actor de su propio desarrollo.

En resumen, el fortalecimiento municipal en Tabasco era indispensable, por ser el municipio la célula básica en donde la participación popular se habría de reflejar activamente en las decisiones que a todos afectaban. Por otro lado, la instancia municipal era garantía de que las respuestas del gobierno estatal estarían al alcance de la mayor parte de la sociedad civil, que de esta forma se constituía en un vigilante permanente.

Descentralizar sería un reconocimiento a la diversidad regional e intraestatal. Fortalecer al municipio era la razón fundamental que obligaba al sistema de planeación a apegarse a criterios democráticos.

En Tabasco, el proceso de descentralización y fortalecimiento municipal "no era casualidad ni magia; podían admitirse muchos calificativos menos uno: novedoso". 8 Detrás de este proceso estaba la organización social del sureste y de Tabasco en particular.

Los historiadores reseñan que un año antes de que la Constitución devolviera a los municipios su capacidad y personalidad jurídica, el gobernador Francisco J. Múgica convocó a elecciones municipales; ${ }^{9} 28$ años antes que el resto del país, Tomás Garrido Canabal

5 Ibidem, p. 37.

${ }^{6}$ La planeación democrática y el fortalecimiento municipal, Publicaciones del Gobierno del Estado de Tabasco, septiembre de 1985, mimeo.

7 Ibidem.

8 González Pedrero, op. cit., p. 49.

9 Para tener un panorama mejor de las modificaciones del gobierno de Múgica, se recomienda ver: Francisco J. Múgica: Hechos, no palabras, Instituto de Estudios Históricos de la Revolución Mexicana, México, 1985. 
reconoció el derecho al voto a la mujer, y en los años 30 el presidente Cárdenas calificó a Tabasco como "el läboratorio de la Revolución Mexicana'. 10

Otro gobernador del estado, Carlos Alberto Madrazo, propuso en los años 60 al Comité Ejecutivo Nacional del PRI el sistema de elecciones directas en las candidaturas municipales. ${ }^{11}$ Muchos se olvidaron que uno de los argumentos más sólidos que se emplearon en contra de este proyecto, fue que resultaba anacrónico. ${ }^{12}$

Estos son los antecedentes mínimos que habrían de tomarse en cuenta al elaborar las estrategias de descentralización en Tabasco. Tal era el proyecto político de la administración de Enrique González Pedrero.

\section{Apunte teórico}

Alexis de Tocqueville decía que hay una estrecha relación entre las autonomías locales, las libertades individuales y la capacidad de cambio de una sociedad.

En esta tradición, Jordi Borja anota que el Estado moderno - tanto los centrales como los periféricos - se ha vuelto más complejo e intervencionista y también mucho más centralizado, lo que lleva a que los órganos políticos locales y regionales pierdan poder y autonomía frente al nivel central de gobierno.

Esta centralización es hoy poco eficiente desde el punto de vista económico global, pues multiplica los costos sociales, los desequilibrios territoriales y las deseconomías de aglomeración; socialmente es injusto, ya que contribuye a aumentar las desigualdades entre los grupos y las áreas territoriales; políticamente es inaceptable, puesto que conduce a un modelo tecno-burocrático estrechamente vinculado a las oligarquías económico-sociales y significa una verdadera expropiación política de las clases populares, que contemplan impotentes el modo en que los derechos formales, las organizaciones sociales y los representantes elegidos sirven de muy poco frente a centros de poder inaccesibles, que toman sus decisiones en forma inapelable sin contar con ellos. ${ }^{13}$

Ante este panorama, urge plantearse - dice Borja- la descentralización político-administrativa como medio adecuado para promover la socialización política de las clases populares y el desarrollo de las libertades individuales, así como las transformaciones socioeconómicas de tendencia igualitaria.

Aquí retomamos la última propuesta de Borja, relativa a la integración de las personas en comunidades de base territorial. No se trata de idealizar al territorio, pero sí de constatar que existen unidades territoriales forjadas por la historia y la geografía, que tienen una identidad sociocultural, un patrimonio y un signo de identidad de la población.

10 Carlos Martínez Assad escribió un amplio estudio de esa época y empleó como título esa frase del presidente Cárdenas: El laboratorio de la revolución. El Tabasco garridista, Siglo XXI Editores, México, 1987.

11 Carlos Martínez Assad y Alicia Ziccardi, "Política y gestión municipal en México", Cuadernos de Inxestigación Social, Iss-unam, Móxico, núm. 18, 1988, pp. 6-7.

12 González Pedrero, op. cit., p. 51.

13 Jordi Borja, Estado y ciudad, PPI, Barcelona, 1988, p. 22. 
Para las clases populares la relación con el territorio y con las estructuras comunitarias es fundamental; no disponen inicialmente de medios para actuar individualmente a niveles más grandes - generales y abstractos-, sino que necesitan estar integrados en estructuras de base.

La recuperación y reconstrucción de estas estructuras territoriales es una cuestión fundamental en un proceso de organización, en su capacidad de intervenir en la política y en las relaciones con las instituciones. Las estructuras de base territorial son un medio para formar alianzas sobre la base de problemas concretos y de establecer relaciones positivas entre las clases trabajadoras y las clases medias, contra las oligarquías, los monopolios y las altas esferas burocráticas.

La propuesta de acción de Jordi Borja debe ser convenientemente desglosada, crearle un puente, darle la posibilidad de articularse.

De forma complementaria citamos la propuesta de Diego Lordello de Mello, acerca de la modernización de los gobiernos locales de América Latina.

La idea central de este administrador público gira en torno a que la modernización de los gobiernos locales será: "la constante adecuación de sus estructuras básicas, de sus poderes y funciones, de su organización interna y de sus procedimientos operativos a las necesidades de las comunidades a que sirven y al cumplimiento de un papel consecuente en el proceso de desarrollo nacional". ${ }^{14}$

Lo anterior implica cuando menos tres puntos fundamentales: a) cuestionar el proceso de toma de decisiones; $b$ ) la manera de involucrar la participación ciudadana en el establecimiento de prioridades, y c) la distribución de los beneficios sociales de la acción gubernamental.

Lordello de Mello plantea de manera muy clara el cuadro patológico de los municipios en América Latina, ${ }^{15}$ y de ahí pasa a indicar las partes medulares del tratamiento: al nivel central del gobierno le corresponde promover cambios estructurales de orden constitucional y legal, y adoptar políticas, planes, programas e instituciones de apoyo técnico y financiero capaces de propiciar las condiciones esenciales para que el municipio se libere de su cuadro patológico.

Al nivel intermedio de gobierno le corresponde complementar las medidas de orden legal y ejercer las acciones necesarias, para la modernización de los gobiernos locales en el ámbito de su competencia.

La responsabilidad de los municipios es la modernización de su organización interna, sus métodos y procesos operativos; teniendo una actitud activa hacia la participación ciudadana, incluso tornando compulsiva la consulta popular en ciertos casos.

Esta modernización de los gobiernos municipales es entendida como parte de una amplia reforma de las instituciones políticas del país.

Las dos propuestas presentadas serán el anclaje de referencia en relación con las actividades de descentralización que se llevaron a cabo en el estado de Tabasco.

14 Diego Lordello de Mello, “Modernización de los gobiernos locales en América Latina", Revista Interamericana de Planificación, vol. XVII, núm. 66, junio de 1983, pp. 185-202.

${ }^{15}$ Ibidem, pp. 188-190. 


\section{Las modificaciones}

La viabilidad de la planeación democrática y del fortalecimiento municipal en Tabasco, dependieron de una equilibrada y realista conjugación de cuatro factores fundamentales: a) un marco jurídico adecuado; $b$ ) disponibilidad de recursos financieros, escrupulosamente controlados; c) una administración pública disciplinada y eficiente, y $d$ ) una activa y comprometida participación social en todas las etapas del proceso. ${ }^{16}$

En cuanto a los ajustes jurídicos, la Constitución del Estado Libre y Soberano de Tabasco se reformó, pudiendo leerse en ella:

\section{Artículo 36.}

Ix. E.l estado organizará un sistema de planeación democrática del desarrollo estatal que imprima solidez, dinamismo, permanencia y equidad, al crecimiento de la economía y a la democratización política, social y cultural del estado.

Artículo 76.

$x$. Los fines del proyecto estatal contenidos en esta Constitución determinarán los objetivos de la planeación. La planeación democrática buscará la participación de los diversos sectores sociales y recogiendo las aspiraciones y demandas de la sociedad para incorporarlas al plan y a los proyectos de desarrollo. Por lo tanto, habrá un plan estatal de desarrollo al que se sujetarán obligatónamente los programas de la administración pública del estadu. La ley facultará al ejecutivo para que pueda establecer los procedimientos de participación y consulta popular en el sistema estatal de planeación y las bases para que el ejecutivo coordine, mediante convenios con los gobiernos de las entidades municipales, e induzca y concerte con los particulares las acciones a realizar. ${ }^{17}$

En la Ley Estatal de Planeación -reglamentaria del artículo 76se especifican los mecanismos que se seguirían en el sistema estatal de planeación. La ley sienta las bases para que cada sector actúe, en consecuencia, con los propósitos del Plan Estatal de Desarrollo (PED), de tal forma que se permita que el gasto público se oriente congruentemente con los objetivos del desarrollo y, por otro lado, que haya transparencia en el manejo de los asuntos públicos.

Unos meses después, en febrero de 1984, circula la nueva Ley Orgánica Municipal, que introduce en la concepción tradicional del municipio prestador de servicios el carácter de promotor de su propio desarrollo. Con esta nueva característica, los municipios del estado participan en igualdad de circunstancias con otros sectores de la administración pública estatal.

A partir de entonces el municipio participó como parte activa del Sistema Estatal de Planificación Democrática (SIESPLADE); si el ámbito de sus responsabilidades habría de abarcar la atención de las necesidades esenciales de la población, era indispensable crear un marco jurídico adecuado.

16 Enrique González Pedrero, Discursos por Tabasco, 1983-1987. Gobierno del estado de Tabasco, Villahermosa, 1988, vol. I, pp. 36-38.

17 Constitución Política del Estado Libre y Soberano de Tabasco, Villahermosa, 1985. 
De tal forma, en los primeros dos artículos de la Ley Orgánica Municipal, se lee:

Artículo 1. El municipio es la base de la división territorial y de la organización política y administrativa del estado.

Artículo 2. La función primordial del municipio es permitir el gobierno democrático de la comunidad para la promoción del desarrollo y para la prestación de los servicios públicos. ${ }^{18}$

De acuerdo con lo anterior, se reconoció que el ayuntamiento reunido en cabildo es la autoridad máxima del municipio y es el responsable del control y vigilancia de los actos emprendidos por el presidente municipal, así como de la formulación y observancia de la reglamentación municipal.

El ayuntamiento no sólo debe reconocer su diversidad comunitaria y administrar con eficacia los recursos que le corresponden, sino estar en condiciones de emitir normas jurídicas básicas que consoliden la cooperación social territorial en cada municipio: el Bando de Policía y Buen Gobierno, el Reglamento de Obras, y los de desarrollo, de seguridad y otros de acuerdo a la especificidad de cada uno de ellos. Este papel es el que se les asigna a los ayuntamientos en la nueva ley.

Las adecuaciones administrativas del fortalecimiento municipal encontraron su expresión más clara en el ámbito de la operación del SIESPLADE, en donde con la acción del COPLADET como espacio de articulación entre la instancia municipal y el poder ejecutivo estatal, se plasmó esta adecuación en los Planes de Desarrollo Municipal, PLADEM.

En los PLADEM se precisan los objetivos generales, las estrategias y las prioridades del desarrollo integral de los municipios de Tabasco; estos documentos contienen previsiones sobre los recursos asignados a tales fines, determinan los instrumentos y responsables de la ejecución y establecen los lineamientos de política de carácter global, sectorial y de servicios municipales.

Por último, la ley establece la posibilidad de suscribir convenios únicos de desarrollo entre el estado y los municipios.

La coordinación está reglamentada por dos instrumentos: el Convenio Único de Desarrollo (CUD) en todo lo que se refiere a las relaciones federación-estado, y el Convenio Único de Desarrollo Municipal (CUDEM) para las acciones entre el estado y los municipios.

El CUDEM fue el primer convenio en su tipo en la república y se formuló "con la plena conciencia de que los municipios no son estados en miniatura, ni los estados pequeñas repúblicas federales". ${ }^{19}$

Estos CUdEM se operan por medio de Programas Municipales de Inversión, cuyos recursos están orientados hacia la atención de prioridades municipales, por lo cual son descentralizados hacia los ayuntamientos para su ejecución. En tal sentido son una herramienta para apoyar el fortalecimiento de los municipios.

18 Ley Orgánica del Municipio, Publicaciones del Gobierno del Estado de Tabasco, Villahermosa, 1984.

${ }_{19}$ González Pedrero, Una democracia, op. cit., p. 32. 


\section{Nueva estructuración del territorio y del espacio político}

El reconocer a la promoción de la democracia comunitaria como la función primordial de los municipios y el que éstos territorialmente abarcan múltiples localidades, permitió que los espacios geográficos de los municipios de Tabasco se dividieran en delegaciones, subdelegaciones, sectores y secciones, a fin de profundizar la democracia y llegar con ella hasta la comunidad misma, que es el origen del Estado mexicano.

El nuevo orden suprimió de manera definitiva las agencias municipales y en cada una de las nuevas instancias estableció la elección democrática del representante político de la comunidad, de base territorial. Democracia y cambios territoriales encontraron una expresión conjunta y concreta en Tabasco.

En Tabasco, descentralización y democracia se asumieron como un nuevo modo de vida; el gobernador González Pedrero lo propuso de la siguiente manera: "El camino más seguro para lograr la descentralización de la vida nacional, en el ámbito político, es el del fortalecimiento de los municipios. No se puede transitar a él con sólo transferir recursos y ámbitos de acción. Es necesario capacitar a los cuadros políticos que harán realidad ese despliegue municipal."20

Al término del primer curso de capacitación municipal (septiembre de 1984) se descentralizaron los servicios educativos y de salud.

Tal proceso pudo ser posible mediante la transformación del Centro de Productividad de Tabasco (CEProtaB), en Instituto de Capacitación para el Desarrollo, lugar en donde se formaran y capacitaran permanentemente a los recursos humanos que trabajaran en los municipios.

El aspecto político del cambio se hizo patente al final de 1985 , ante el cambio de presidentes municipales y de diputados al Congreso del estado. La estrategia seguida en el interior del PRI - partido sin oposición real en el estado en ese año-fue la consulta a las bases y la elección interna de candidatos.

"La consulta a las bases en 1985 era una vuelta a los orígenes. No se trataba de copiar del pasado, sino de retomarlo, de aprovechar la experiencia." 21 Y de aprovechar la circunstancia, podríamos agregar.

La consulta resultó una experiencia que enriqueció la vida política del estado. Para la elección de candidatos a presidentes municipales jugaron un papel más importante los comités seccionales que los sectores del partido; esto quiere decir que contó menos el pertenecer y el padrinazgo del sector que la militancia en la base del partido y la voluntad y el apoyo popular.

En cambio, para la selección de candidatos a las curules del Congreso, los sectores jugaron su papel; ahí se tomaron en cuenta "ciertas posiciones sectoriales y, por tanto, se conjugó la consulta directa con el sistema de convenciones, con lo cual el partido mantuvo su equilibrio dinámico entre sector y sección". ${ }^{22}$

Quedaba por dar en Tabasco un paso mayor, transitar de la democracia electoral representativa a la democracia participativa, a la que actúa por y para el desarrollo.

El reto está pendiente.

${ }^{20}$ González Pedrero, Discursos por. .., op. cit., vol. II, pp. 175-176.

21 González Pedrero, Una democracia..., op. cit., p. 50.

22 Ibidem, p. 65. 


\section{¿Hacia dónde?}

Tal y como lo anotaron Jordi Borja y Diego Lordello de Mello, la participación democrática, la descentralización política y la democracia electoral están inscritas en un proceso de renovación permanente, en constante adecuación a los tiempos y a la realidad concreta.

En Tabasco la democracia no se presentó a saltos, se cimentó en la participación de la ciudadanía organizada en grupos de base territorial y éstos a su vez coordinados en lo político-administrativo por los municipios, como la instancia de gobierno más inmediata y como espacio de discusión y de construcción de una democracia que transita de lo electoral a la participación activa.

En Tabasco el proceso electoral de 1985 reflejó la calidad de un proceso democrático, al mismo tiempo que fue una especie de síntesis de una relación madura entre pueblo y gobierno. Las palabras de González Pedrero son contundentes: "La democracia no se encuentra en el tintero de alguna pluma, sino en la aportación que cada uno pueda y quiera ofrecer para mejorar la convivencia. La democracia es una realidad con rostros y nombres, la democracia es de carne y hueso."'23

La modernización y descentralización de los municipios de Tabasco en el periodo 1983-87 incluyó un abanico de aspectos que se tradujeron en acciones legales administrativas, en la planeación del gasto y en el control financiero, la reestructuración territorial y la participación en la búsqueda de una nueva etapa en la democracia.

Sin embargo, ante las transformaciones democráticas quedan algunas cuestiones que deben ser estudiadas:

1. ¿La supresión del liderazgo carismático por uno burocráticoinstitucional en los municipios, destierra también prácticas clientelísticas tradicionales?

2. La sujeción a una norma burocrática centralizada para la elaboración de planes y programas de acción municipal, ¿no lleva implícita una centralización de la toma de decisión?

3. ¿La introducción de un nuevo modelo de participación hasta la comunidad, alteró las relaciones sociales y de dominación existentes; provocó conflictos intergrupales?

4. En las elecciones de 1985, ¿cuáles fueron las consecuencias del desplazamiento de los dos sectores y cómo se reconstituyen éstos a partir de las posiciones en el Congreso estatal?

5. ¿De qué forma se derivan y aplazan las actividades espontáneas de las comunidades?

6. ¿Cuál fue la respuesta de las "viejas burocracias" municipales, ante los cambios ocurridos en la descentralización?

Se puede concluir, después de la experiencia de Tabasco, que cuando la mayoría de los presidentes municipales del país se elijan democráticamente, se habrá dado un paso firme en la construcción de otra sociedad. Tal situación podrá ser el mejor paso para solicitar desde ese nivel la descentralización y la modernización de este nivel de gobierno. Al Estado sólo quedará tener voluntad política y no tenerle miedo al pueblo. 